\title{
Association between Asp299Gly and Thr399Ile Polymorphisms in Toll-Like Receptor 4 Gene and Type 2 Diabetes Mellitus: Case-Control Study and Meta- Analysis
}

Taís Silveira Assmann ${ }^{1,2}$, Natália Emerim Lemos ${ }^{1,2}$, Letícia de Almeida Brondani ${ }^{1,2}$, Rodrigo Carlessi ${ }^{1,2}$, Carmen Maldonado-Bernal ${ }^{3,4}$, Miguel $^{2}$ Cruz $^{3,4}$, Luis Henrique Canani ${ }^{1,2}$ and Daisy Crispim ${ }^{1,2^{*}}$

${ }^{1}$ Endocrine Division, Hospital de Clínicas de Porto Alegre. Porto Alegre, Rio Grande do Sul, Brazil

${ }^{2}$ Postgraduate Program in Medical Sciences: Endocrinology, Universidade Federal do Rio Grande do Sul. Porto Alegre, Rio Grande do Sul, Brazil

${ }^{3}$ Research Laboratory in Immunology and Proteomics, Hospital Infantil de México Federico Gómez, Mexico City, México

${ }^{4}$ Biochemistry Research Unit, Hospital de Especialidades, Centro Médico Nacional SXXI, IMSS, México City, México

\begin{abstract}
Objective: This paper describes a case-control study and a meta-analysis conducted to determine whether the TLR4 Asp299Gly (rs4986790) and Thr399lle (rs4986791) polymorphisms are associated with type 2 diabetes mellitus (T2DM).

Methods: In the case-control study were enrolled 1683 T2DM patients and 584 nondiabetic subjects from Brazil. A literature search was conducted in order to identify studies that investigated associations between the referred TLR4 polymorphisms and T2DM. Pooled odds ratios (OR) were calculated for allele contrast and dominant inheritance models.

Results: In the case-control study, genotype and allele frequencies of the Asp299Gly and Thr399lle polymorphisms differed between T2DM patients and nondiabetic subjects $(P<0.05)$. Moreover, the presence of the minor alleles of these polymorphisms were significantly associated with protection for T2DM, after adjusting for ethnicity, under a dominant model [Asp299Gly: OR=0.68 (95\% Cl 0.49-0.94); Thr399lle: OR=0.65 (95\% Cl 0.46-0.90)]. Seven studies were eligible for inclusion in the meta-analysis. Meta-analysis results showed that the Asp299Gly polymorphism was associated with T2DM protection [OR=0.68 $(95 \% \mathrm{Cl} 0.46-1.00)$, allele contrast model]. Stratification by ethnicity revealed that both polymorphisms were associated with T2DM protection under allele contrast and dominant models in Brazilian population but not in Europeans

Conclusions: In our case-control study, we were able to demonstrate a possible association between the TLR4 Asp299Gly and Thr399lle polymorphisms and protection for T2DM. In agreement, the meta-analysis results showed an association of the Asp299Gly polymorphism with T2DM protection in the whole group, and associations of the Asp299Gly and Thr399lle polymorphisms with T2DM protection in the Brazilian group but not in European descendent. This is the largest TLR4 meta-analysis performed so far. In other ethnicities further studies with large sample size are necessary to confirm these associations in different ethnicities as well as to elucidate the roles possibly played by these polymorphisms in the pathogenesis of T2DM.
\end{abstract}

Keywords: Type 2 diabetes mellitus; Toll-like receptor 4; DNA polymorphisms; Case-control study; Meta-analysis

\section{Introduction}

Type 2 Diabetes Mellitus (T2DM) is a chronic and complex disease caused by a combination of Insulin Resistance (IR) and impaired insulin secretion from pancreatic beta-cells [1]. According to the "meta inflammation" (metabolically triggered inflammation) hypothesis, both T2DM and IR are considered as states of preclinical chronic lowgrade inflammation [2], resulting from changes in the innate immunity response, which is the first line of defense against viruses, bacteria and fungi $[3,4]$. Therefore, polymorphisms in genes that encode proteins related to the innate immune system, such as the toll-like receptors (TLRs), could influence the immune response as well as the development of T2DM [5]

TLRs are evolutionary conserved Pattern-Recognition Receptors (PRRs) that play a key role in the activation of innate immune response by recognizing highly conserved pathogen-associated molecular patterns (PAMPs), such as the Lipopolysaccharide (LPS) component of gram-negative bacteria $[4,6]$. Human orthologs are known to comprise at least 10 members [7]. Each TLR family member recognizes a specific pathogen component and, upon activation, triggers a signaling cascade leading to the production of inflammatory cytokines, releasing of antimicrobial peptides, and activation of the adaptive immune response $[8,9]$.

Toll-like receptor 4 (TLR4) recognizes LPS as a ligand [9], and is expressed in macrophages, airway epithelia, adipose tissue, skeletal muscle, pancreas, and vascular endothelial and smooth muscle cells [10]. It also interacts with endogenous ligands such as free-fatty acids, heat shock proteins 60 and 70, fibrinogen and fibronectin, which are elevated in T2DM patients [10-12]. Moreover, TLR4 activation seems

*Corresponding author: Daisy Crispim, Endocrine Division - Hospital de Clínicas de Porto Alegre, Rua Ramiro Barcelos 2350, Prédio 12, $4^{\circ}$ andar, Zip Code: 90035-003, Porto Alegre-RS, Brazil; Phone: + 55513359 8127; E-mail: dcmoreira@hcpa.ufrgs.br

Received May 12, 2014; Accepted August 25, 2014; Published August 30, 2014

Citation: Assmann TS, Lemos NE, de Almeida Brondani L, Carlessi R, Maldonado-Bernal C, et al. (2014) Association between Asp299Gly and Thr399lle Polymorphisms in Toll-Like Receptor 4 Gene and Type 2 Diabetes Mellitus: CaseControl Study and Meta-Analysis. J Diabetes Metab 5: 427 doi:10.4172/21556156.1000427

Copyright: (c) 2014 Assmann TS, et al. This is an open-access article distributed under the terms of the Creative Commons Attribution License, which permits unrestricted use, distribution, and reproduction in any medium, provided the original author and source are credited. 
Citation: Assmann TS, Lemos NE, de Almeida Brondani L, Carlessi R, Maldonado-Bernal C, et al. (2014) Association between Asp299Gly and Thr399lle Polymorphisms in Toll-Like Receptor 4 Gene and Type 2 Diabetes Mellitus: Case-Control Study and Meta-Analysis. J Diabetes Metab 5: 427 doi:10.4172/2155-6156.1000427

Page 2 of 9

to play a critical role in the pathogenesis of IR and T2DM in both clinical and experimental conditions [10,13-15].

Two functional polymorphisms in the TLR4 gene (Asp299Gly and Thr399Ile) were reported as being associated with LPS hyporesponsiveness [16]. Since their identification, these polymorphisms have been investigated for their association with T2DM and IR; however, results from such studies have been contradictory [5,17-22]. Considering that T2DM is caused by interactions between a large number of environmental and genetic factors, it is not unexpected that some genetic association studies will fail to confirm associations with the disease even if they actually exist. Indeed, T2DM has been described as a "geneticist's nightmare" and it may be the case that it will be necessary to study huge numbers of patients in order to elucidate the associations between even a single polymorphism and the disease [23]. Therefore, as part of the ongoing effort to examine the hypothesis that TLR4 polymorphisms are associated with T2DM risk, we performed a case-control study in a Brazilian population, followed by a metaanalysis of the literature on the subject.

\section{Material and Methods}

\section{Case-control study}

Population: The diabetic sample comprised 1683 T2DM patients participating in a multicenter study that began recruiting patients in Southern Brazil in 2002. That project was aimed to study risk factors for T2DM and its chronic complications. It initially included four centers in University hospitals located in the Brazilian state of Rio Grande do Sul: Grupo Hospitalar Conceição, Hospital São Vicente de Paula, Hospital Universitário de Rio Grande, and Hospital de Clínicas de Porto Alegre. A detailed description of that study can be found elsewhere [24]. T2DM was diagnosed according to the American Diabetes Association criteria [1]. The main characteristics of the T2DM patients were as follows: mean age was $58.5 \pm 10.4$ years, mean T2DM duration was $12.3 \pm 9.3$ years, mean age at T2DM diagnosis was $46.3 \pm 11.4$ years, mean glycated hemoglobin (HbAlc) was $7.8 \pm 1.7 \%$, and mean body mass index (BMI) was $28.9 \pm 5.2 \mathrm{~kg} / \mathrm{m}^{2}$. Males comprised $47.4 \%$ of the sample and $72.2 \%$ of all patients had Arterial Hypertension $(\mathrm{AH})$.

The nondiabetic group comprised 584 healthy volunteers attending the blood donation facility at Hospital de Clínicas de Porto Alegre (Porto Alegre, Brazil; males $=51.0 \%$; mean age $=44.0 \pm 7.8$ years). None of these individuals had diabetes or a family history of it. The ethnic group was defined based on self-classification, and the ethnic proportion between the two samples was as follows: $20.1 \%$ of black patients in the T2DM group and $12.3 \%$ of black subjects in the nondiabetic group.

A standard questionnaire was used to collect information regarding age, age at T2DM diagnosis, and drug treatment. All T2DM patients underwent detailed physical and laboratory evaluations, as previously described $[25,26]$. Briefly, they were weighed bare feet, wearing light outdoor clothes and their height was measured. BMI was calculated as weight $(\mathrm{kg}) /$ height $^{2}$ (meters). Office Blood Pressure (BP) was measured in sitting position, on the left arm, after a 5 -min rest by a trained researcher, with a mercury sphygmomanometer. The mean of two measurements taken $1 \mathrm{~min}$ apart was used to calculate both systolic and diastolic BP. AH was defined as BP levels higher than $140 / 90 \mathrm{mmHg}$ at the initial visit and at two follow-up visits within 1 month of the initial visit, or if the presence of $\mathrm{AH}$ was previously registered on medical records.

Serum and plasma samples from T2DM patients were taken after a 12 hours of fasting for laboratory analyses. Plasma glucose levels were determined using the glucose oxidase method. HbAlc measurements were performed by different methods and results were traceable to the Diabetes Control and Complications Trial (DCCT) method by off-line calibration or through conversion formulae [27]

Total plasma cholesterol, HDL cholesterol and triglycerides were assayed using enzymatic methods. Nondiabetic individuals did not undergo any of these tests.

The information obtained from this study did not influence patients' diagnosis or treatment. The study was approved by the Ethic Committee in Research from Hospital de Clínicas de Porto Alegre and all subjects provided written informed consent.

Genotyping: DNA was extracted from peripheral blood leucocytes by a standardized salting-out procedure [28]. TLR4 Asp299Gly (rs4986790; A/G) and Thr399Ile (rs4986791; C/T) polymorphisms were genotyped using primers and probes contained in the 40x Human Custom TaqMan Genotyping Assay (Life Technologies, Foster City, CA). Sequences of primers and probes were: 5'-ACCATTGAAGAATTCCGATTAGCATACT-3' (forward); 5'-CACCAGGGAAAATGAAGAAACATTTGT-3' (reverse); 5'-CCTCGATGGTATTATT-3' (FAM dye); 5'-CTACCTCGATGATATTATT-3' (VIC dye) for the Asp299Gly polymorphism, and 5'-GAGTTTCAAAGGTTGCTGTTCTCAA-3' (forward); 5'-GGTAATAACACCATTGAAGCTCAGATCT-3' (reverse); 5'-TTAGGCTGATTGTCCC-3' (FAM dye); 5'-TTAGGCTGGTTGTCCC-3' (VIC dye) for the Thr399Ile polymorphism. Reactions were conducted in 384-well plates, in a total of $5 \mu \mathrm{L}$ volume using $2 \mathrm{ng}$ of genomic DNA, TaqMan Genotyping Master Mix 1x (Life Technologies) and Custom TaqMan Genotyping Assay 1x. Plates were then loaded in a real-time PCR thermal cycler (ViiA-7 Real time PCR System; Life Technologies) and heated for $10 \mathrm{~min}$ at $95^{\circ} \mathrm{C}$, followed by 50 cycles of $95^{\circ} \mathrm{C}$ for $15 \mathrm{~s}$ and $60^{\circ} \mathrm{C}$ for $1 \mathrm{~min}$.

Statistical analyses for case-control study: Allele frequencies were determined by gene counting and departures from the Hardy-Weinberg Equilibrium (HWE) were analyzed using $\chi^{2}$ tests. Allele and genotype frequencies were compared between groups using $\chi^{2}$ tests. Clinical and laboratory characteristics were compared between genotype groups by using unpaired Student's t-test, One-way ANOVA or $\chi^{2}$, as appropriate. Variables with normal distribution are presented as mean \pm SD or percentage. Variables with skewed distribution were log-transformed before analyses and are represented as median (minimum - maximum values).

The magnitude of associations of the Asp299Gly and Thr399Ile polymorphisms with T2DM were estimated using OR (95\% CI). Multivariate logistic regression analyses were performed to assess the independent association of each of the two analyzed polymorphisms with T2DM, adjusting for ethnicity and age. Results for which the $P$ value was under 0.05 were considered statistically significant. Bonferroni correction was used to account for multiple comparisons. These statistical analyses were performed using SPSS version 18.0 (SPSS, Chicago, IL).

Between all pairs of biallelic loci, we examined widely used measures of linkage disequilibrium, Lewontin's $\mathrm{D}^{\prime}\left|\mathrm{D}^{\prime}\right|$ and $\mathrm{r}^{2}$ [29]. The haplotype constructed from the combination of the two TLR4 polymorphisms and their frequencies were inferred using the software Phase 2.1, which implements a Bayesian statistical approach. We also used Phase 2.1 to compare the distributions of the different TLR4 haplotypes between T2DM patients and nondiabetic subjects through permutation analysis of 10,000 random replicates [30].

Power calculations were done using the software PEPI, version 
Citation: Assmann TS, Lemos NE, de Almeida Brondani L, Carlessi R, Maldonado-Bernal C, et al. (2014) Association between Asp299Gly and Thr399lle Polymorphisms in Toll-Like Receptor 4 Gene and Type 2 Diabetes Mellitus: Case-Control Study and Meta-Analysis. J Diabetes Metab 5: 427 doi:10.4172/2155-6156.1000427

Page 3 of 9

4.0 , and showed that this study has a power of approximately $80 \%$ at a significance level of 0.05 to detect an OR of 0.65 or less (for the presence of the minor alleles).

\section{Meta-Analysis}

\section{Selection criteria and search strategy}

PubMed, Cochrane and Embase repositories were searched to identify all articles that analyzed associations between T2DM and at least one of the two polymorphisms of interest. The following medical subject headings (MeSH) were used for this search: ("diabetes mellitus, type 2" OR "diabetes mellitus") AND ("polymorphism, genetic" OR "polymorphism, single-stranded conformational" OR "polymorphism, single nucleotide" OR "polymorphism, restriction fragment length" OR "amplified fragment length polymorphism analysis" OR "DNA copy number variations") AND ("mutation" OR "frameshift mutation" OR "mutation rate" OR "INDEL mutation" OR "mutation, missense" OR "point mutation" OR "codon, nonsense") AND ("toll-like receptor 4" OR "toll-like receptors"). The search was restricted to human studies and English or Spanish language articles and was completed on January 10,2014 . All of the articles identified were searched manually to identify any other relevant citations. This study was designed and described in agreement with widely used guidelines for execution of systematic reviews and meta-analyses [31,32].

\section{Study selection and data extraction}

Eligibility evaluation was made by title and abstracts review and when abstracts did not provide sufficient data, the full text of the paper was retrieved for analysis. This was done independently in a standardized manner by two investigators (T.S.A and N.E.L). Disagreements were resolved by discussion between them and when required a third reviewer (D.C.) was consulted. Articles were excluded from the analysis if the genotype frequencies in the control group deviated from those predicted by the HWE and if they did not have enough data to estimate an OR with $95 \%$ CI. If data were duplicated and had been published more than once, the most complete study was chosen $[25,26,33,34]$.
Necessary information from each study was independently extracted by two investigators (T.S.A. and N.E.L.) using a standardized extraction form, and consensus was sought in all extracted items. When consensus could not be achieved, differences in data extraction were decided by reading the original publication. The data extracted from each study was as follows: (1) characteristics of study participants (including name of first author, publication year, number of subjects in case and control groups, mean age, gender, BMI, ethnicity, age at diagnosis, fasting plasma glucose, total cholesterol, HDL cholesterol, LDL cholesterol, systolic BP, diastolic BP); (2) case and control definitions; (3) polymorphism frequencies [including genotype and allele distributions in case and control groups and OR (95\% CI)].

\section{Quality assessment}

To ascertain the validity of each included study, two investigators (T.S.A and N.E.L.) independently assessed the quality using the Newcastle-Ottawa Scale (NOS) [32]. The NOS contains eight items divided into three dimensions: selection, comparability, and exposure. For each item, a sequence of answer options is provided. A star scoring system is used to allow a semi-quantitative evaluation of paper quality, such that the highest quality studies are given a maximum of one star for each item, with exception of the item related to comparability, which allows two stars to be given. Therefore, the total NOS score can vary from zero to nine stars.

\section{Statistical analysis for meta-analysis}

Control subjects' genotype distributions were tested for conformity with HWE using a goodness-of-fitness $\chi^{2}$ test. Gene-disease associations were measured using OR (95\% CI) estimation based on allele contrast and dominant model of inheritance $[35,36]$. Other inheritance models were not analyzed due to the rarity of the minor alleles. Heterogeneity was tested using $\chi^{2}$-based Cochran's $Q$ statistic and inconsistency was assessed with the $\mathrm{I}^{2}$ metric, as previously described $[25,26,33,34]$. Briefly, heterogeneity was considered statistically significant at $\mathrm{P}<0.10$ for the $\mathrm{Q}$ statistic and $\mathrm{I}^{2}>50 \%$ for the $\mathrm{I}^{2}$ metric statistics. Where significant heterogeneity was detected, the DerSimonian and Laird random effect model (REM) was used to calculate OR (95\% CI) for each study and

\begin{tabular}{|c|c|c|c|c|}
\hline TLR4 polymorphisms & T2DM patients & Non diabetic subjects & Unadjusted *P value & Adjusted OR (95\% CI) / §P value \\
\hline Asp299Gly (A/G) & $\mathrm{n}=1672$ & $\mathrm{n}=570$ & & \\
\hline $\mathrm{A} / \mathrm{A}$ & $1531(91.6)$ & $499(87.5)$ & 0.005 & 1 \\
\hline$A / G$ & $138(8.2)$ & $66(11.6)$ & & $0.68(0.5-0.93) / 0.015$ \\
\hline G/G & $3(0.2)$ & $5(0.9)$ & & $0.20(0.05-0.82) / 0.026$ \\
\hline A & 0.96 & 0.93 & 0.002 & \\
\hline G & 0.04 & 0.07 & & \\
\hline \multicolumn{5}{|l|}{ Dominant Model } \\
\hline $\mathrm{A} / \mathrm{A}$ & $1531(91.6)$ & $499(87.5)$ & 0.006 & 1 \\
\hline$A / G+G / G$ & $141(8.4)$ & $71(12.5)$ & & $0.68(0.49-0.94) / 0.019$ \\
\hline Thr399lle (C/T) & $n=1683$ & $n=584$ & & \\
\hline $\mathrm{C} / \mathrm{C}$ & $1550(92.0)$ & $514(88.0)$ & 0.004 & 1 \\
\hline $\mathrm{C} / \mathrm{T}$ & $131(7.8)$ & $65(11.1)$ & & $0.67(0.49-0.92) / 0.012$ \\
\hline $\mathrm{T} / \mathrm{T}$ & $3(0.2)$ & $5(0.9)$ & & $0.20(0.05-0.84) / 0.027$ \\
\hline C & 0.96 & 0.94 & 0.001 & \\
\hline $\mathrm{T}$ & 0.04 & 0.06 & & \\
\hline \multicolumn{5}{|l|}{ Dominant Model } \\
\hline $\mathrm{C} / \mathrm{C}$ & $1550(92.0)$ & $514(88.0)$ & 0.004 & 1 \\
\hline $\mathrm{C} / \mathrm{T}+\mathrm{T} / \mathrm{T}$ & $134(8.0)$ & $70(12.0)$ & & $0.65(0.46-0.90) / 0.009$ \\
\hline
\end{tabular}

Data are presented as number of carriers (\%) or proportion. * $P$ values were computed using $X^{2}$ tests to compare T2DM patients and nondiabetic subjects. $\S P$ values adjusted for ethnicity in a logistic regression analysis.

Table 1: Genotype and allele distributions of TLR4 Asp299Gly and Thr399lle polymorphisms in T2DM patients and nondiabetic subjects. 
Citation: Assmann TS, Lemos NE, de Almeida Brondani L, Carlessi R, Maldonado-Bernal C, et al. (2014) Association between Asp299Gly and Thr399lle Polymorphisms in Toll-Like Receptor 4 Gene and Type 2 Diabetes Mellitus: Case-Control Study and Meta-Analysis. J Diabetes Metab 5: 427 doi:10.4172/2155-6156.1000427

Page 4 of 9

for the pooled effect; where heterogeneity was not significant, the fixed effect model (FEM) was used for this evaluation [37]. Meta-regression and sensitivity analyses were performed to identify important studies with a significant impact on inter-study heterogeneity [25,26,33,34]. The factors investigated by meta-regression were age, BMI and gender. Sensitivity analyses were done after stratifying the studies by ethnicity, given that the TLR4 polymorphisms show variable distributions across different ethnic groups. Risk of publication bias was evaluated using funnel plot graphics, analyzed both visually and by using the Begg and Egger test [38]. $\mathrm{P}<0.10$ was considered indicative of statistically significant publication bias. All statistical analyses were performed using Stata 11.0 software (StataCorp, College Station, TX, USA).

\section{Results}

\section{Case-control study}

Genotype and allele frequencies of the TLR4 Asp299Gly and Thr399Ile polymorphisms in T2DM patients and nondiabetic subjects are depicted in Table 1. The frequency of the G allele of the Asp299Gly polymorphism was 0.05 in white subjects and 0.04 in black subjects $(\mathrm{P}=$ 0.238), while the frequency of the $T$ allele of the Thr399Ile polymorphism was 0.046 in white and 0.047 in black subjects $(P=0.920)$. All genotypes were in agreement with those predicted by the HWE $(\mathrm{P}>0.05)$. Both genotype and allele frequencies of the two analyzed polymorphisms were differently distributed between T2DM patients and nondiabetic subjects after Bonferroni corrections (Table 1). Genotype frequencies of both polymorphisms remained significantly associated with T2DM after adjustment for ethnicity and age (Table 1). In agreement with this data, the presence of the minor alleles of the Asp299Gly and Thr399Ile polymorphisms were significantly associated with protection for T2DM under a dominant model of inheritance, adjusting for ethnicity and age $[\mathrm{OR}=0.68$ (95\% CI 0.49-0.94) and $\mathrm{OR}=0.65$ (95\% CI 0.46-0.90), respectively; Table 1]. Of note, after the exclusion of black patients from the sample, the presence of the minor alleles was still associated with protection for T2DM in white subjects under a dominant model of inheritance [Asp299Gly: OR=0.61 (95\% CI 0.43-0.86); Thr399Ile: OR $=0.64(95 \%$ CI $0.45-0.91)]$.

The frequencies of the different haplotypes produced by the combination of the TLR4 Asp299Gly and Thr399Ile polymorphisms in T2DM patients and nondiabetic subjects are shown in Table 2. Four haplotypes were inferred in both groups of subjects, and the distributions of these haplotypes were statistically different between T2DM patients and nondiabetic subjects $(P=0.023)$. Differences in the frequencies of the two most common haplotypes (A-C and G-T), which had opposite alleles for the two studied positions, explain this observation. Interestingly, the prevalence of T2DM was lower as more minor alleles were present in the subjects $(\mathrm{P}$-trend $=0.022)($ Table 2$)$. The presence of four minor alleles was associated with the highest protection for T2DM [OR $=0.21(95 \%$ CI 0.05-0.86)].

\begin{tabular}{|l|c|c|c|}
\hline & T2DM patients $(\mathbf{n}=\mathbf{3 2 7 4})$ & Non diabetic subjects $\mathbf{( n = 1 1 2 4 )}$ & $\mathbf{P}^{*}$ value \\
\hline A-C & 0.937 & 0.952 & 0.023 \\
\hline A-T & 0.009 & 0.006 & \\
\hline G-C & 0.011 & 0.011 & \\
\hline G-T & 0.052 & 0.031 & \\
\hline
\end{tabular}

$\mathrm{n}=$ number of chromosomes. The first letter of the haplotype refers to Asp299Gly (A/G) and the second to Thr399lle (C/T). ${ }^{*} \mathrm{P}$ values for the comparisons of haplotypic frequencies between T2DM patients and nondiabetic subjects were calculated using permutation tests (10,000 replications).

Table 2: TLR4 gene haplotypes in T2DM patients and nondiabetic subjects.

\begin{tabular}{|l|c|c|c|}
\hline & A/A & A/G + G/G & $\mathbf{P}^{*}$ value \\
\hline Age (years) & $56.1 \pm 11.3$ & $59.0 \pm 11.8$ & 0.007 \\
\hline Gender (\% males) & 49.3 & 51.9 & 0.592 \\
\hline Ethnicity (\% black) & 22.7 & 16.6 & 0.076 \\
\hline Age at diagnosis (years) & $46.2 \pm 11.3$ & $47.6 \pm 12.4$ & 0.284 \\
\hline BMI (kg/m²) & $28.9 \pm 5.2$ & $28.6 \pm 5$ & 0.594 \\
\hline HbA1c (\%; mmol/L) & $7.2 \pm 2.2(55 \pm 17)$ & $6.8 \pm 2.1(51 \pm 16)$ & 0.166 \\
\hline Systolic BP (mmHg) & $142.2 \pm 24.1$ & $143.3 \pm 24.8$ & 0.653 \\
\hline Diastolic BP (mmHg) & $85.8 \pm 14.3$ & $84.6 \pm 12.6$ & 0.407 \\
\hline Total cholesterol (mmol/L) & $5.3 \pm 1.3$ & $5.4 \pm 1.2$ & 0.557 \\
\hline HDL cholesterol (mmol/L) & $2.2 \pm 0.6$ & $2.4 \pm 1.1$ & 0.250 \\
\hline Triglycerides (mmol/L) & $3.6(1.1-18.6)$ & $3.3(1.5-7.7)$ & 0.836 \\
\hline Diabetic nephropathy (\%) & 52.2 & 51.2 & 0.916 \\
\hline Diabetic retinopathy (\%) & 49.6 & 49.4 & 0.999 \\
\hline
\end{tabular}

Data are mean $\pm \mathrm{SD}$, median (minimum-maximum values) or $\%$. BMI, body mass index; BP, blood pressure; HbA1c, glycated hemoglobin; T2DM, type 2 diabetes mellitus. * $P$ values are according to $\mathrm{X} 2$ test or $\mathrm{t}$-test as appropriate. Only $\mathrm{P}$ values lower than the Bonferroni threshold $(P=0.0038)$ were considered statistically significant.

Table 3: Clinical and laboratory characteristics of T2DM patients, broken down by the presence of the G allele of the TLR4 Asp299Gly polymorphism (dominant model).

The TLR4 Asp299Gly and Thr399Ile polymorphisms are in moderate linkage disequilibrium $\left(\left|\mathrm{D}^{\prime}\right|=0.85 ; \mathrm{r}^{2}=0.73\right)$ in our samples. For that reason, in Table 3, we present only clinical and laboratorial characteristics of T2DM patients according to the presence of the minor allele of the Asp299Gly polymorphism. Gender, age, age at T2DM diagnosis, HbA1c, systolic and diastolic BP, and lipid profile did not differ between patients categorized by the presence of the 299Gly allele after Bonferroni corrections. Similar results were found for the Thr399Ile polymorphism (data not shown).

\section{Meta-analysis}

One-hundred seventy-four possible relevant citations were retrieved by searching the electronic databases, and 146 of them were excluded following the reading of titles and abstracts. Twenty-eight articles seemed to be eligible after this phase and, then, their full texts were evaluated. Nevertheless, after cautious analysis of the full texts, another 22 papers were excluded owing to missing information, ineligible study designs or because they investigated other TLR4 polymorphisms. Eleven articles fulfilled the eligibility criteria; however, only 7 were included in the meta-analysis: 6 that had been identified through the database searches [5,17-21], in addition to the case-control study we described above (Figure S1). The other four studies evaluated the Asp299Gly and Thr399Ile polymorphisms in Asian populations, but they could not be included in the meta-analysis since only the ancestral genotypes were found [39-42].

Clinical characteristics for each individual paper are described in Table S1. All of these studies analyzed the Asp299Gly polymorphism (3583 cases / 3813 controls), while 6 studies investigated the Thr399Ile polymorphism (3262 cases / 1846 controls). Table S2 lists genotype and allele distributions and ORs ( $95 \%$ CI) for the TLR4 polymorphisms in case and control groups from the different studies reviewed. The quality of each study is shown in Table S3. The highest quality studies were awarded nine stars. In general, most studies were considered as having good quality selection, comparability and exposure. None of the papers scored less than six stars and $80 \%$ of them had seven or eight stars.

Table 4 summarizes the results of the pooled analyses for associations between TLR4 Asp299Gly and Thr399Ile polymorphisms 
Citation: Assmann TS, Lemos NE, de Almeida Brondani L, Carlessi R, Maldonado-Bernal C, et al. (2014) Association between Asp299Gly and Thr399lle Polymorphisms in Toll-Like Receptor 4 Gene and Type 2 Diabetes Mellitus: Case-Control Study and Meta-Analysis. J Diabetes Metab 5: 427 doi:10.4172/2155-6156.1000427

Page 5 of 9

\begin{tabular}{|c|c|c|c|c|c|c|c|}
\hline \multirow[t]{2}{*}{ Inheritance model } & \multirow[t]{2}{*}{ n studies } & \multirow[t]{2}{*}{$\mathrm{n}$ cases } & \multirow[t]{2}{*}{ n controls } & \multirow[t]{2}{*}{$I^{2}(\%)$} & \multirow[t]{2}{*}{ Pooled OR $(95 \% \mathrm{CI})$} & \multicolumn{2}{|c|}{ Sensibility analysis* } \\
\hline & & & & & & $I^{2}(\%)$ & Pooled OR $(95 \% \mathrm{Cl})$ \\
\hline \multicolumn{8}{|l|}{ Asp299Gly } \\
\hline $\begin{array}{l}\text { Allele contrast } \\
\text { European descendent } \\
\text { Brazilians } \\
\text { Mexicans }\end{array}$ & $\begin{array}{l}7 \\
4 \\
2 \\
1\end{array}$ & $\begin{array}{c}3904 \\
1700 \\
1883 \\
321\end{array}$ & $\begin{array}{c}4348 \\
3043 \\
770 \\
535\end{array}$ & $\begin{array}{c}81.5 \\
87.5 \\
4.4 \\
-\end{array}$ & $\begin{array}{l}0.68(0.46-1.00) \\
0.64(0.34-1.22) \\
0.59(0.45-0.79) \\
1.35(0.78-2.32)\end{array}$ & 77.2 & $0.60(0.41-0.88)$ \\
\hline $\begin{array}{l}\text { Dominant } \\
\text { European descendent } \\
\text { Brazilians } \\
\text { Mexicans }\end{array}$ & $\begin{array}{l}5 \\
2 \\
2 \\
1\end{array}$ & $\begin{array}{c}3285 \\
1081 \\
1883 \\
321\end{array}$ & $\begin{array}{l}2374 \\
1069 \\
770 \\
535\end{array}$ & $\begin{array}{c}64.6 \\
0.0 \\
0.0 \\
64.6\end{array}$ & $\begin{array}{l}0.89(0.6-1.30) \\
1.16(0.80-1.68) \\
0.62(0.47-0.82) \\
1.36(0.78-2.37)\end{array}$ & 27.9 & $0.68(0.48-0.96)$ \\
\hline \multicolumn{8}{|l|}{ Thr399lle } \\
\hline $\begin{array}{l}\text { Allele contrast } \\
\text { European descendent } \\
\text { Brazilians } \\
\text { Mexicans }\end{array}$ & $\begin{array}{l}6 \\
3 \\
2 \\
1\end{array}$ & $\begin{array}{c}3581 \\
1367 \\
1895 \\
319\end{array}$ & $\begin{array}{c}2384 \\
1062 \\
784 \\
538\end{array}$ & $\begin{array}{l}81.5 \\
90.5 \\
54.3 \\
-\end{array}$ & $\begin{array}{l}0.65(0.39-1.07) \\
0.65(0.24-1.79) \\
0.46(0.19-1.12) \\
1.13(0.64-2.00)\end{array}$ & 79.3 & $0.56(0.32-0.97)$ \\
\hline $\begin{array}{l}\text { Dominant } \\
\text { European descendent } \\
\text { Brazilians } \\
\text { Mexicans }\end{array}$ & $\begin{array}{l}5 \\
2 \\
2 \\
1\end{array}$ & $\begin{array}{c}3295 \\
1081 \\
1895 \\
319\end{array}$ & $\begin{array}{l}1971 \\
649 \\
784 \\
538\end{array}$ & $\begin{array}{c}59.7 \\
0.0 \\
50.0 \\
-\end{array}$ & $\begin{array}{l}0.85(0.58-1.26) \\
1.14(0.78-1.65) \\
0.60(0.45-0.81) \\
1.13(0.63-2.03)\end{array}$ & 49.6 & $0.66(0.40-1.10)$ \\
\hline
\end{tabular}

Where significant heterogeneity was detected $\left(I^{2}>50 \%\right)$, the DerSimonian and Laird Random Effect Model (REM) was used to calculate OR (95\% Cl) for each individual study and for the pooled effect; where heterogeneity was not significant, the Fixed Effect Model (FEM) was used for this calculation. * Sensibility analysis excluding the Buraczynska et al. [19] or to eliminate the heterogeneity.

Table 4: Meta-analysis pooled measures for associations between the TLR4 Asp299Gly and Thr399lle polymorphisms and the susceptibility to T2DM.

and susceptibility to T2DM. The Asp299Gly polymorphism was associated with T2DM protection when assuming an allele contrast model (REM OR 0.68, 95\% CI 0.46-1.00). Furthermore, stratification by ethnicity showed that, assuming an allele contrast model, the 299Gly allele was significantly associated with protection for T2DM in Brazilian population [OR=0.59 (95\% CI 0.45-0.79), but not in Europeans (Figure 1A). When assuming the dominant model, the 299Gly allele was associated with T2DM protection in Brazilians [0.62 (95\% CI 0.47-0.82)], but not in Europeans or in the whole sample (Table 4). In the whole sample the Thr399Ile polymorphism was not associated with T2DM under allele contrast or dominant models (Table 4). However, stratification by ethnicity showed that the 399Ile allele was associated with T2DM protection in Brazilians under allele contrast $[\mathrm{OR}=0.58$ (95\% CI 0.44-0.76); Figure $1 \mathrm{~B}]$ and dominant $[\mathrm{OR}=0.60$ (95\% CI $0.45-0.81)]$ models, whereas it was not associated with the disease in Europeans for the two analyzed models (Table 4). There was only one study performed in Mexicans, showing that the two analyzed polymorphisms were not associated with $\mathrm{T} 2 \mathrm{DM}$ in this population (Figure 1)

There was significant heterogeneity among studies investigating the TRL4 polymorphisms when assuming allele contrast and dominant models ( $\mathrm{I}^{2}>50 \%$ for the entire sample), as it can be observed in Table 4 . To investigate this result in more details, gender, age and BMI were used as covariates in the meta-regression analyses performed for the two TLR4 polymorphisms. None of the covariates used in univariate metaregression analyses could independently explicate the heterogeneity observed for the allele contrast and dominant models (data not shown).

Sensitivity analyses were performed with the aim of estimating the influence of each study on the meta-analysis data. This was done by repeating the meta-analysis, but omitting a given study each time. The results showed that one paper [19] was responsible for the heterogeneity observed in the meta-analyses of Asp299Gly and Thr399Ile polymorphisms under dominant models. Thus, significant heterogeneity was abolished by exclusion of this study from the analysis regarding this inheritance model (Table 4). However, the exclusion of this study only changed significantly the result obtained for the Asp299Gly polymorphism [OR 0.68 (95\% CI 0.48-0.96)]. Heterogeneity observed for allele contrast models could not be eliminated by the exclusion of any study. At last, no significant publication bias was identified for allele contrast and dominant models in the total sample (Figures S2 and S3).

\section{Discussion}

According to previously published evidence, TLR4 activation in adipocytes, skeletal muscles and liver induces up-regulation of proinflammatory pathways related to IR and, consequently, T2DM $[13,14,43,44]$. Furthermore, a recent study showed that treatment with LPS inhibits insulin gene expression in rat and human pancreatic beta-cells in a TLR4-dependent manner and via NF- $\kappa B$ signaling [45]. Importantly, the effects of LPS on the insulin gene in human islets were observed at concentrations similar to the circulating levels achieved during endotoxemia, suggesting that direct repression of the insulin gene might contribute to the metabolic disturbances associated with alterations of microbiota [45].

In agreement with this evidence, some studies have reported that the TLR4 Asp299Gly and Thr399Ile polymorphisms are associated with T2DM [5,10,46,47]; however, results have been inconsistent. The contradictory results could be partially explained by the fact that the associations between these polymorphisms and T2DM are influenced by ethnic backgrounds [48]. Another source of confusion could come from independent analysis of these polymorphisms without considering that they are in tight linkage disequilibrium [49]. Moreover, the inconsistencies might be explained by studies with small sample sizes, lacking enough statistical power. Thus, in an attempt to arrive at a more definitive conclusion about the associations between these TLR4 polymorphisms and T2DM, we performed a case-control study followed by a meta-analysis of genetic association studies on this subject.

Our case-control study showed that the presences of the minor alleles of TLR4 Asp299Gly and Thr399Ile polymorphisms are associated with protection for T2DM in a South Brazilian population. It is worth mentioning that the frequencies of these polymorphisms in our samples were similar to those frequencies observed in another study performed in a Southeast Brazilian population [5]. Bagarolli et al. [5] also reported an association of these two polymorphisms with protection for T2DM. 
Citation: Assmann TS, Lemos NE, de Almeida Brondani L, Carlessi R, Maldonado-Bernal C, et al. (2014) Association between Asp299Gly and Thr399lle Polymorphisms in Toll-Like Receptor 4 Gene and Type 2 Diabetes Mellitus: Case-Control Study and Meta-Analysis. J Diabetes Metab 5: 427 doi:10.4172/2155-6156.1000427

A

\section{Authors}

Europeans

Illig

Kolek

Buraczynska

Manolakis

Subtotal $($ I-squared $=87.5 \%, p=0.000))$

Brazilians

Bagaroli

This study

Subtotal $\quad($ I-squared $=4.4 \%, p=0.307$ )

Mexicans

Maldonado-Bernal

Subtotal $\quad($ I-squared $=\%, p=$.)

Overall $(\mathrm{I}$-squared $=81.5 \%, p=0.000)$
$\%$

OR $(95 \% \mathrm{Cl}) \quad$ Weight

$0.92(0.50,1.68) \quad 12.89$

$0.57(0.44,0.74) \quad 17.26$

$1.36(0.85,2.16) \quad 14.73$

$0.23(0.13,0.42) \quad 13.24$

$0.64(0.34,1.22) \quad 58.13$

$0.42(0.20,0.87) \quad 5.39$

$0.63(0.47,0.84) \quad 24.35$

$0.59(0.45,0.79) \quad 29.73$

$1.35(0.78,2.32) \quad 12.14$

$1.35(0.78,2.32) \quad 12.14$

$0.68(0.46,1.00) \quad 100.00$
B

Authors

Europeans

Illig

Buraczynska

Manolakis

Subtotal $\quad($ I-squared $=90.5 \%, p=0.000)$ )

Brazilians

Bagaroli

This study

Subtotal $\quad(\mathrm{I}$-squared $=54.3 \%, p=0.139)$

Mexicans

Maldonado-Bernal

Subtotal $\quad($ I-squared $=\%, p=$.)

Overall $\quad(\mathrm{I}$-squared $=81.5 \%, p=0.000)$
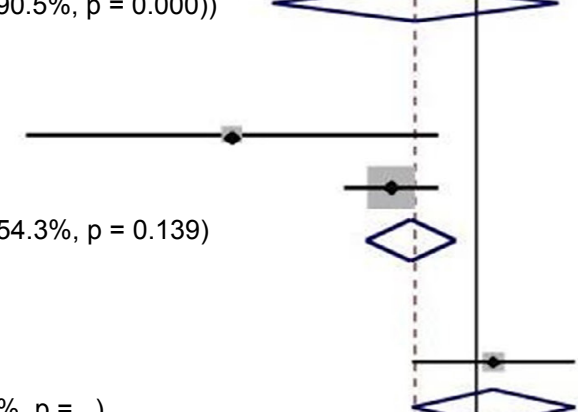

$1.13(0.64,2.00) \quad 14.25$

$1.13(0.64,2.00) \quad 14.25$

$0.65(0.39,1.07) \quad 100.00$
$\%$

OR $(95 \% \mathrm{Cl}) \quad$ Weight

$0.92(0.50,1.68) \quad 15.90$

$1.24(0.78,1.97) \quad 17.70$

$0.23(0.13,0.42) 15.24$

$0.65(0.24,1.79) \quad 48.84$

$0.23(0.06,0.83) \quad 4.74$

$0.62(0.46,0.83) \quad 40.41$

$0.58(0.44,0.76) \quad 45.15$

Figure 1: A) Forest plots showing individual and pooled ORs (95\% Cl) for the associations between the TLR4 Asp299Gly polymorphism and T2DM under an allele contrast inheritance model. The areas of the squares reflect the weight of each individual study and the diamonds illustrate the random-effects summary ORs (95\% $\mathrm{Cl})$. B) Forest plots showing individual and pooled ORs $(95 \% \mathrm{Cl})$ for the associations between the TLR4 Thr399lle polymorphism and T2DM under an allele contrast inheritance model. The areas of the squares reflect the weight of each individual study and the diamonds illustrate the random-effects summary ORs (95\% $\mathrm{Cl})$. 
Citation: Assmann TS, Lemos NE, de Almeida Brondani L, Carlessi R, Maldonado-Bernal C, et al. (2014) Association between Asp299Gly and Thr399lle Polymorphisms in Toll-Like Receptor 4 Gene and Type 2 Diabetes Mellitus: Case-Control Study and Meta-Analysis. J Diabetes Metab 5: 427 doi:10.4172/2155-6156.1000427

Page 7 of 9

Seven studies with 3904 T2DM patients and 4348 controls were included in our meta-analysis of the Asp299Gly polymorphism, and 6 studies (3581 cases and 2384 controls) were included in the metaanalysis of the Thr399Ile polymorphism. The meta-analysis results showed an association between the minor allele of the Asp299Gly polymorphism and protection for T2DM in the whole sample $[\mathrm{OR}=0.68$ (95\% CI 0.46-1.00); allele contrast model]. In contrast, the Thr399Ile polymorphism was not associated with the disease in the whole sample. After stratification by ethnicity, the minor alleles of the Asp299Gly and Thr399Ile polymorphisms were significantly associated with protection for T2DM in Brazilian populations, but not in European descendents. Moreover, only one study evaluated these polymorphisms in Mexicans, and it did not show any association with T2DM [20].

Heterogeneity is potentially a significant problem when interpreting the data of meta-analyses of genetic association studies, and the present meta-analysis showed significant inter-study heterogeneity for both polymorphisms analyzed in the total group under allele contrast and dominant inheritance models. To examine this in greater deepness, sensitivity analyses were performed repeating the meta-analysis omitting a given study each time. The exclusion of the data from Buraczynska et al. [19] significantly decreased the heterogeneity observed in the meta-analyses of the Asp299Gly polymorphism under a dominant model. Moreover, after the exclusion of this study, the presence of the 299Gly allele was associated with T2DM protection [OR $0.68(95 \%$ CI 0.48-0.96)]. Meta-regression analyses were not able to explain the heterogeneity observed for the whole group. This heterogeneity could be explained by differences in genotyping methods, sample selection or gene-environment interactions. Therefore, without full information on the metabolic and clinical data of the studies included here, we could not completely eliminate the possibility that the heterogeneity observed might decrease our power to detect true associations.

It is noteworthy that one previous meta-analysis investigated the association between the TLR4 Asp299Gly polymorphism and metabolic disorders, and it included 6 studies totalizing 1696 cases with T2DM and/or metabolic syndrome and 3388 controls [22]. The authors reported a significant association between the 299Gly allele and protection for metabolic disorders [OR=0.57 (95\% CI 0.35-0.93)], which is in agreement with our data. However, after stratification by ethnicity, this association was maintained in Caucasians [OR $=0.50$ (95\% CI 0.28-0.99)], but not in samples having mixed ethnicity, which conflicts with our data showing an association only in Brazilians. We believe that a possible reason for this discrepancy is that the metaanalysis of Belforte et al. [22] included one study [50] where cases were patients with metabolic syndrome instead of patients with T2DM. They did not inform the number of patients with metabolic syndrome that also had T2DM. The inclusion of a study that analyzed a different outcome (metabolic syndrome) could have increased the heterogeneity of their data and, consequently, changed the results. Furthermore, they did not include the study of Buraczynska et al. [19] from 2009, which shows no association between the Asp299Gly polymorphism and T2DM.

It is supposed that the ability to respond efficiently to different ligands might be impaired by polymorphisms in the TLR4 gene [20]. In this context, the mutated alleles of the Asp299Gly and Thr399Ile polymorphisms have been shown to change the ligand-binding site of the TLR4, often resulting in hyporesponsiveness of the immune system [16]. Recently, Figueroa et al. [48] reported that the 299Gly allele causes a deficient recruitment of the adapters MyD88 and TRIF to the TLR4, consequently leading to a LPS-hyporesponsive phenotype.
In agreement with these data, individuals carrying the 299Gly allele have lower levels of proinflammatory cytokines, acute-phase reactants, and soluble adhesion molecules, such as interleukin 6 and fibrinogen [51]. Moreover, Asp299Gly and Thr399Ile polymorphisms have been reported to be associated with different diseases such as gastric cancer, hepatitis $\mathrm{C}$ virus-induced hepatocellular carcinoma, Crohn's Disease and ulcerative colitis $[16,52,53]$, supporting a functional role for these polymorphisms. Also, these two polymorphisms seem to modify the pattern of inflammatory cytokines and chemokines in the gastric mucosa, suggesting a contribution to the clinical outcome of $\mathrm{H}$. pylori infection [54].

Our literature search identified four studies that evaluated the Asp299Gly and Thr399Ile polymorphisms in Asian populations, but they could not be included in the present meta-analysis because only the ancestral genotypes were found [39-42]. The lower frequency of the minor alleles of these TLR4 polymorphisms in Asians will require larger sample sizes to detect any statistically significant association with T2DM. Recently, the TLR4 rs11536889 (+3725G/C) polymorphism was reported as being associated with protection for T2DM in a Chinese population [42]. This polymorphism is located at the 3' untranslated region of the gene and seems to induce a lower rate of TLR4 mRNA translation [55]. Further studies are necessary to evaluate the association between the TLR4 rs11536889 and T2DM in other populations.

Some factors could have interfered with the findings of our casecontrol study. First, we cannot rule out the possibility of population stratification bias when analyzing our samples, even though both T2DM patients and non-diabetic subjects were recruited from the same hospital, the results were adjusted for ethnicity, and the exclusion of black subjects from the whole sample did not change the association observed, thus reducing the risk of false-positive/negative associations due to this bias. Second, we did not perform a replication of the observed association in another Brazilian sample, although our data is in agreement with a previous study performed in Southeast Brazilian subjects [5]. In the same way, the results of our meta-analysis should be interpreted within the context of a few limitations. First, meta-analysis is prone to publication bias, and although we have attempted to trace unpublished studies, we cannot be sure that small negative studies were overlooked. Moreover, we did not detect any significant publication bias in our analysis, showing that our data is statistically reliable. Second, because of the difficulty in getting the full texts of articles published in several languages, we only included studies published in English and Spanish. Third, inter-studies heterogeneity is common problem in meta-analyses of genetic association studies [56], and our metaanalyses showed significant inter-study heterogeneity for both TLR4 polymorphisms analyzed. Although meta-regression analyses were not able to explain this heterogeneity, sensitivity analyses did not change significantly the reported associations.

In conclusion, our results indicate that the TLR4 Asp299Gly and Thr399Ile polymorphisms are associated with protection for T2DM in Brazilians. The meta-analysis results showed an association of the Asp299Gly polymorphism with T2DM protection in the whole group, and associations of the Asp299Gly and Thr399Ile polymorphisms with T2DM protection in the Brazilian group but not in European descendent. This is the largest TLR4 meta-analysis performed so far. In other ethnicities further studies with large sample size are necessary to confirm these associations in different ethnicities as well as to elucidate the roles possibly played by these polymorphisms in the pathogenesis of T2DM. To this date, TLR4 activation seems to play a critical role in the pathogenesis of IR and T2DM in both clinical and experimental 
Citation: Assmann TS, Lemos NE, de Almeida Brondani L, Carlessi R, Maldonado-Bernal C, et al. (2014) Association between Asp299Gly and Thr399lle Polymorphisms in Toll-Like Receptor 4 Gene and Type 2 Diabetes Mellitus: Case-Control Study and Meta-Analysis. J Diabetes Metab 5: 427 doi:10.4172/2155-6156.1000427

conditions [10,13-15]. Thus, as suggested by Reina et al. [14], future strategies aimed at reducing TLR4 expression, or at blocking TLR4 signaling may prove useful in enhancing insulin sensitivity in subjects with IR.

\section{Acknowledgement}

This study was partially supported by grants from the Fundação de Amparo à Pesquisa do Estado do Rio Grande do Sul (FAPERGS), the Conselho Nacional de Desenvolvimento Científico e Tecnológico (CNPq), the Fundo de Incentivo à Pesquisa e Eventos (FIPE) at the Hospital de Clínicas de Porto Alegre, and the Coordenação de Aperfeiçoamento de Pessoal de Nível Superior (CAPES). D.C. and L.H.C. are recipients of scholarships from CNPq. The funders had no role in study design, data collection and analysis, decision to publish, or preparation of the manuscript.

\section{Financial Support}

Fundação de Amparo à Pesquisa do Estado do Rio Grande do Sul (FAPERGS), Conselho Nacional de Desenvolvimento Científico e Tecnológico (CNPq), Fundo de Incentivo à Pesquisa e Eventos (FIPE) at Hospital de Clínicas de Porto Alegre, and Coordenação de Aperfeiçoamento de Pessoal de Nível Superior (CAPES). D.C. and L.H.C. are CNPq grant recipients.

\section{References}

1. American Diabetes Association (2013). Diagnosis and Classification of Diabetes Mellitus. Diabetes Care 35: 64-71.

2. Hotamisligil GS (2006) Inflammation and metabolic disorders. Nature 444: 860867

3. Kolb H, Mandrup-Poulsen T (2005) An immune origin of type 2 diabetes? Diabetologia 48: 1038-1050.

4. Meylan E, Tschopp J, Karin M (2006) Intracellular pattern recognition receptors in the host response. Nature 442: 39-44.

5. Bagarolli RA, Saad MJ, Saad ST (2010) Toll-like receptor 4 and inducible nitric oxide synthase gene polymorphisms are associated with Type 2 diabetes. J Diabetes Complications 24: 192-198.

6. Arancibia SA, Beltrán CJ, Aguirre IM, Silva P, Peralta AL, et al. (2007) Toll-like receptors are key participants in innate immune responses. Biol Res 40: 97 112

7. Zarember KA, Godowski PJ (2002) Tissue expression of human Toll-like receptors and differential regulation of Toll-like receptor mRNAs in leukocytes in response to microbes, their products, and cytokines. J Immunol 168: 554-561.

8. Akira S, Takeda K, Kaisho T (2001) Toll-like receptors: critical proteins linking innate and acquired immunity. Nat Immunol 2: 675-680.

9. Takeda K, Akira S (2005) Toll-like receptors in innate immunity. Int Immuno 17: $1-14$.

10. Shi H, Kokoeva MV, Inouye K, Tzameli I, Yin H, et al. (2006) TLR4 links innate immunity and fatty acid-induced insulin resistance. J Clin Invest 116: 30153025 .

11. Sasu S, LaVerda D, Qureshi N, Golenbock DT, Beasley D (2001) Chlamydia pneumoniae and chlamydial heat shock protein 60 stimulate proliferation of human vascular smooth muscle cells via toll-like receptor 4 and p44/p42 mitogen-activated protein kinase activation. Circ Res 89: 244-250

12. Smiley ST, King JA, Hancock WW (2001) Fibrinogen stimulates macrophage chemokine secretion through toll-like receptor 4. J Immunol 167: 2887-2894.

13. Kim F, Pham M, Luttrell I, Bannerman DD, Tupper J, et al. (2007) Toll-like receptor-4 mediates vascular inflammation and insulin resistance in dietinduced obesity. Circ Res 100: 1589-1596.

14. Reyna SM, Ghosh S, Tantiwong P, Meka CS, Eagan P, et al. (2008) Elevated toll-like receptor 4 expression and signaling in muscle from insulin-resistant subjects. Diabetes 57: 2595-2602.

15. Dasu MR, Devaraj S, Park S, Jialal I (2010) Increased toll-like receptor (TLR) activation and TLR ligands in recently diagnosed type 2 diabetic subjects. Diabetes Care 33: 861-868.

16. Arbour NC, Lorenz E, Schutte BC, Zabner J, Kline JN, et al. (2000) TLR4 mutations are associated with endotoxin hyporesponsiveness in humans. Na Genet 25: 187-191.
17. Illig T, Bongardt F, Schöpfer A, Holle R, Müller S, et al. (2003) The endotoxin receptor TLR4 polymorphism is not associated with diabetes or components of the metabolic syndrome. Diabetes 52: 2861-2864.

18. Kolek MJ, Carlquist JF, Muhlestein JB, Whiting BM, Horne BD, et al. (2004) Tolllike receptor 4 gene Asp299Gly polymorphism is associated with reductions in vascular inflammation, angiographic coronary artery disease, and clinical diabetes. Am Heart J 148: 1034-1040.

19. Buraczynska M, Baranowicz-Gaszczyk I, Tarach J, Ksiazek A (2009) Tolllike receptor 4 gene polymorphism and early onset of diabetic retinopathy in patients with type 2 diabetes. Hum Immunol 70: 121-124.

20. Maldonado-Bernal C, Trejo-de la O A, Sánchez-Contreras ME, WacherRodarte N, Torres J, et al. (2011) Low frequency of Toll-like receptors 2 and 4 gene polymorphisms in Mexican patients and their association with type 2 diabetes. Int J Immunogenet 38: 519-523.

21. Manolakis AC, Kapsoritakis AN, Tiaka EK, Sidiropoulos A, Gerovassili A, et al. (2011) TLR4 gene polymorphisms: evidence for protection against type 2 diabetes but not for diabetes-associated ischaemic heart disease. Eur $\mathrm{J}$ Endocrinol 165: 261-267.

22. Belforte FS, Coluccio Leskow F, Poskus E, Penas Steinhardt A (2013) Toll-like receptor 4 D299G polymorphism in metabolic disorders: a meta-analysis. Mo Biol Rep 40: 3015-3020.

23. Stolerman ES, Florez JC (2009) Genomics of type 2 diabetes mellitus: implications for the clinician. Nat Rev Endocrinol 5: 429-436.

24. Canani LH, Capp C, Ng DP, Choo SG, Maia AL, et al. (2005) The fatty acidbinding protein-2 A54T polymorphism is associated with renal disease in patients with type 2 diabetes. Diabetes 54: 3326-3330.

25. Brondani LA, Assmann TS, de Souza BM, Bouças AP, Canani LH, et al. (2014) Meta-analysis reveals the association of common variants in the uncoupling protein (UCP) 1-3 genes with body mass index variability. PLoS One 9: e96411.

26. Bouças AP, Brondani LA, Souza BM, Lemos NE, de Oliveira FS, et al. (2013) The A allele of the rs1990760 polymorphism in the IFIH1 gene is associated with protection for arterial hypertension in type 1 diabetic patients and with expression of this gene in human mononuclear cells. PLoS One 8: e83451.

27. Camargo JL, Zelmanovitz T, Paggi A, Friedman R, Gross JL (1998) Accuracy of conversion formulae for estimation of glycohaemoglobin. Scand J Clin Lab Invest 58: 521-528.

28. Lahiri DK, Nurnberger JI Jr (1991) A rapid non-enzymatic method for the preparation of HMW DNA from blood for RFLP studies. Nucleic Acids Res 19: 5444 .

29. Hedrick PW (1987) Gametic disequilibrium measures: proceed with caution Genetics 117: 331-341.

30. Stephens M, Smith NJ, Donnelly P (2001) A new statistical method for haplotype reconstruction from population data. Am J Hum Genet 68: 978-989.

31. Stroup DF, Berlin JA, Morton SC, Olkin I, Williamson GD, et al. (2000) Metaanalysis of observational studies in epidemiology: a proposal for reporting Meta-analysis Of Observational Studies in Epidemiology (MOOSE) group. JAMA 283: 2008-2012.

32. Stang A (2010) Critical evaluation of the Newcastle-Ottawa scale for the assessment of the quality of nonrandomized studies in meta-analyses. Eur $\mathrm{J}$ Epidemiol 25: 603-605.

33. de Almeida Brondani L, de Souza BM, Assmann TS, Bouças AP, Bauer AC, et al. (2014) Association of the UCP polymorphisms with susceptibility to obesity: case-control study and meta-analysis. Mol Biol Rep 41: 5053-5067.

34. de Souza BM, Brondani LA, Bouças AP, Sortica DA, Kramer CK, et al. (2013) Associations between UCP1 -3826A/G, UCP2 -866G/A, Ala55Val and Ins/Del, and UCP $3-55 \mathrm{C} / \mathrm{T}$ polymorphisms and susceptibility to type 2 diabetes mellitus: case-control study and meta-analysis. PLoS One 8: e54259.

35. Minelli C, Thompson JR, Abrams KR, Thakkinstian A, Attia J (2005) The choice of a genetic model in the meta-analysis of molecular association studies. Int $\mathrm{J}$ Epidemiol 34: 1319-1328.

36. Zintzaras E, Lau J (2008) Synthesis of genetic association studies for pertinent gene-disease associations requires appropriate methodological and statistical approaches. J Clin Epidemiol 61: 634-645.

37. Higgins JP, Thompson SG (2002) Quantifying heterogeneity in a meta-analysis Stat Med 21: 1539-1558. 
Citation: Assmann TS, Lemos NE, de Almeida Brondani L, Carlessi R, Maldonado-Bernal C, et al. (2014) Association between Asp299Gly and Thr399lle Polymorphisms in Toll-Like Receptor 4 Gene and Type 2 Diabetes Mellitus: Case-Control Study and Meta-Analysis. J Diabetes Metab 5: 427 doi:10.4172/2155-6156.1000427

Page 9 of 9

38. Egger M, Davey Smith G, Schneider M, Minder C (1997) Bias in meta-analysis detected by a simple, graphical test. BMJ 315: 629-634.

39. Kim YS, Hwang YJ, Kim SY, Yang SM, Lee KY, et al. (2008) Rarity of TLR4 Asp299Gly and Thr399lle polymorphisms in the Korean population. Yonsei Med J 49: 58-62.

40. Lai P-b, Zhang L, Yan S-j, Yang L-y (2010) Absence of TLR4 Asp299Gly and Thr399lle Polymorphisms in Chinese Han Population With Type 2 Diabetes China: Labmedicine. pp. 559-562.

41. Cai H, Cai J, Tao G (2013) Association of toll-like receptor 4 polymorphisms with type 2 diabetes mellitus. APMIS 121: 605-611.

42. Jiang ZS, Wang SX, Jia HX, Wang J, Liu YT (2013) Association of toll-like receptor 4 polymorphisms with type 2 diabetes mellitus. Inflammation 36: 251 257.

43. Song MJ, Kim KH, Yoon JM, Kim JB (2006) Activation of Toll-like receptor 4 is associated with insulin resistance in adipocytes. Biochem Biophys Res Commun 346: 739-745

44. Bilan PJ, Samokhvalov V, Koshkina A, Schertzer JD, Samaan MC, et al. (2009) Direct and macrophage-mediated actions of fatty acids causing insulin resistance in muscle cells. Arch Physiol Biochem 115: 176-190.

45. Amyot J, Semache M, Ferdaoussi M, Fontés G, Poitout V (2012) Lipopolysaccharides impair insulin gene expression in isolated islets of Langerhans via Toll-Like Receptor-4 and NF-I'º signalling. PLoS One 7: e36200.

46. Tsukumo DM, Carvalho-Filho MA, Carvalheira JB, Prada PO, Hirabara SM, et al. (2007) Loss-of-function mutation in Toll-like receptor 4 prevents diet-induced obesity and insulin resistance. Diabetes 56: 1986-1998.

47. Wong FS, Wen L (2008) Toll-like receptors and diabetes. Ann N Y Acad Sci 1150: $123-132$
48. Figueroa L, Xiong Y, Song C, Piao W, Vogel SN, et al. (2012) The Asp299Gly polymorphism alters TLR4 signaling by interfering with recruitment of MyD88 and TRIF. J Immunol 188: 4506-4515.

49. Ferwerda B, McCall MB, Verheijen K, Kullberg BJ, van der Ven AJ, et al. (2008) Functional consequences of toll-like receptor 4 polymorphisms. Mol Med 14 346-352.

50. Penas-Steinhardt A, Barcos LS, Belforte FS, de Sereday M, Vilariño J, et al. (2012) Functional characterization of TLR4 +3725 G/C polymorphism and association with protection against overweight. PLoS One 7: e50992.

51. Kiechl S, Lorenz E, Reindl M, Wiedermann CJ, Oberhollenzer F, et al. (2002) Toll-like receptor 4 polymorphisms and atherogenesis. N Engl J Med 347: 185192.

52. Shen X, Shi R, Zhang H, Li K, Zhao Y, et al. (2010) The Toll-like receptor 4 D299G and T399l polymorphisms are associated with Crohn's disease and ulcerative colitis: a meta-analysis. Digestion 81: 69-77.

53. de Oliveira JG, Silva AE (2012) Polymorphisms of the TLR2 and TLR4 genes are associated with risk of gastric cancer in a Brazilian population. World $J$ Gastroenterol 18: 1235-1242.

54. Trejo-de la O A, Torres J, Pérez-Rodríguez M, Camorlinga-Ponce M, Luna LF et al. (2008) TLR4 single-nucleotide polymorphisms alter mucosal cytokine and chemokine patterns in Mexican patients with Helicobacter pylori-associated gastroduodenal diseases. Clin Immunol 129: 333-340.

55. Sato K, Yoshimura A, Kaneko T, Ukai T, Ozaki Y, et al. (2012) A single nucleotide polymorphism in 3'-untranslated region contributes to the regulation of Toll-like receptor 4 translation. J Biol Chem 287: 25163-25172.

56. Munafò MR, Flint J (2004) Meta-analysis of genetic association studies. Trends Genet 20: 439-444. 